\title{
Pengembangan Kemampuan Menulis Ilmiah Berbantuan Manajemen Referensi Mendeley bagi Guru-Guru SMA/Sederajat di Kabupaten Bintan
}

\author{
Fitriah Khoirunnisa*, Ardi Widhia Sabekti, Inelda Yulita \\ Universitas Maritim Raja Ali Haji, Jl. Politeknik, KM. 24, Senggarang, Tanjung Pinang, Kota \\ Tanjung Pinang, Kepulauan Riau 29115, Indonesia \\ *Corresponding author email: fitriahk@umrah.ac.id
}

\section{Diterima: Maret 2019; Revisi: April 2019; Diterbitkan: Mei 2019}

\begin{abstract}
Abstrak
Sebuah karya tulis ilmiah yang berisi karya inovatif dalam proses pembelajaran sangat diperlukan oleh guru-guru sebagai syarat kenaikan pangkat dalam pengembangan profesi mereka, termasuk guru-guru SMA/sederajat di Kabupaten Bintan. Namun, pada umumnya mereka mengalami kendala dalam membuat karya tulis ilmiah disebabkan kesulitan dalam mencari sumber referensi yang relevan dengan topik penelitian, keterbatasan pengetahuan dalam TIK, dan kesulitan dalam mengolah kalimat agar tidak terdeteksi sebagai kegiatan plagiasi. Tujuan kegiatan ini agar para guru SMA/sederajat di Kabupaten Bintan dapat membuat karya tulis ilmiah yang sesuai kaedah penulisan yang baik dan bebas plagiasi dengan bantuan manajemen referensi Mendeley. Pelaksanaan kegiatan ini dalam bentuk workshop/pelatihan dengan metode ceramah, diskusi, tanya jawab, dan projek. Kegiatan dilakukan selama dua hari dalam bentuk workshop dan dua hari dalam bentuk tugas mandiri. Kegiatan pengabdian kepada masyarakat ini dianggap berhasil karena sebesar $80 \%$ peserta mengalami peningkatan pengetahuan tentang manajemen referensi Mendeley dan mampu mengaplikasikannya ke dalam bentuk karya tulis ilmiah yang bebas plagiasi.
\end{abstract}

Kata Kunci: Karya tulis, Mendeley, Kabupaten Bintan

\section{Assistance for the Implementation of GMP in Tutok Shrimp Processing in Kuala Pusing Kapal Village}

\begin{abstract}
A scientific paper containing innovative work in the learning process is very much needed by teachers as a condition of promotion in their professional development, including high school / equivalent teachers in the Bintan Regency. However, in general, they experience difficulties in making scientific papers due to difficulties in finding reference sources that are relevant to the research topic, limited knowledge in $I C T$, and difficulty in processing sentences so as not to be detected as plagiarism activities. The purpose of this activity is for high school / equivalent teachers in Bintan Regency to be able to make scientific papers in accordance with good writing methods and to be free of plagiarism with the help of Mendeley's reference management. The implementation of this activity is in the form of workshops/training using lecture, discussion, question and answer, and project methods. The activity was carried out for two days in the form of a workshop and two days in the form of an independent assignment. This community service activity was considered successful because $80 \%$ of the participants experienced an increase in knowledge about Mendeley's reference management and were able to apply it in the form of plagiarismfree scientific papers.
\end{abstract}

Keywords: GMP; Tutok shrimp paste, standardization; Kuala Pusing Kapal

How to Cite: Khoirunnisa, F., Sabekti, A., \& Yulita, I. (2021). Pengembangan Kemampuan Menulis IImiah Berbantuan Manajemen Referensi Mendeley bagi Guru-Guru SMA/Sederajat di Kabupaten Bintan. Lumbung Inovasi: Jurnal Pengabdian kepada Masyarakat, 4(1), 8-13. doi:https://doi.org/10.36312/linov.v4i1.438 


\section{PENDAHULUAN}

Kabupaten Bintan merupakan salah satu kabupaten yang berada dalam provinsi Kepulauan Riau yang berjarak lebih kurang 80-90 km dari pusat kota Tanjungpinang. Waktu yang diperlukan untuk mencapai daerah ini sekitar 1 jam 30 menit dari kota Tanjungpinang. Keunggulannya, daerah ini termasuk salah satu daerah terdepan dan terluar karena letaknya yang strategis yang berbatasan dan berhadapan langsung dengan negara lain (Malaysia dan Singapura) tanpa terhalangi oleh pulau-pulau lainnya sehingga perlu mendapat perhatian khusus terutama dalam bidang pendidikan. Keberhasilan suatu pendidikan dapat dilihat dari kompetensi yang dapat dicapai siswa dan kompetensi yang dapat dicapai para pendidiknya, dalam hal ini adalah guru. Terdapat empat kompetensi guru berdasarkan Undang-Undang Nomor 14 Tahun 2005 tentang Guru dan Dosen Pasal 10 Ayat 1, di antaranya kompetensi pedagogik, kompetensi kepribadian, kompetensi sosial, dan kompetensi profesional (UU, 2005).

Salah satu kegiatan yang mendukung kompetensi profesional seorang guru adalah dengan mengembangkan keprofesionalan secara berkelanjutan dengan melakukan tindakan reflektif serta memanfaatkan TIK dalam berkomunikasi dan mengembangkan diri, yaitu dengan melakukan penelitian yang berkaitan dengan pengembangan proses pembelajaran yang dituangkan dalam bentuk karya tulis ilmiah. Karya tulis ilmiah merupakan hal yang sangat dibutuhkan oleh para akademisi, termasuk guru untuk mengembangkan ilmu pengetahuan yang dimilikinya sehingga dapat menyumbangkan pemikiran-pemikiran ilmiahnya melalui suatu tulisan. Dalam menulis suatu karya tulis ilmiah, tentunya akan sangat dihindari tindakan plagiasi baik yang disengaja maupun tidak disengaja karena kekurang hatihatian dalam membuat sitasi. Oleh karena itu, keberadaan sebuah perangkat lunak yang berfungsi sebagai "citation \& reference manager" merupakan sebuah kebutuhan.

Cara untuk memanajemen referensi agar terhindar dari tindakan-tindakan plagiasi dalam suatu karya tulis ilmiah adalah dengan menggunakan aplikasi Mendeley. Mendeley merupakan sebuah perangkat lunak yang berfungsi untuk mengintegrasikan "citation \& reference manager" ke dalam jejaring sosial (Agustiana, Tika, Wibawa, 2018). Perangkat lunak ini dapat memudahkan penulis untuk melacak keaslian referensi yang digunakannya. Di samping itu, Mendeley juga dapat membantu penulis dalam mengolah dokumen referensi yang dimiliki, membuat pengelompokan berdasarkan topik/kategori tertentu, sekaligus meretrieve metadata yang terdapat di dalam dokumen. Mendeley merupakan salah satu aplikasi yang harus dikuasi oleh mahasiswa, dosen, guru atau peneliti lain dalam membuat karya ilmiah, karena dengan mendekey akan dapat membantu dalam penyisipan, penulisan, dan pemformatan sitasi (Aji, 2016). Selain itu, aplikasi ini juga dapat juga digunakan untuk mengelola file artikel jurnal online yang merupakan output dari sebuah karya ilmiah (Windarto et al., 2018).

Berdasarkan wawancara tim pelaksana Pengabdian Masyarakat kepada Ketua MGMP (Musyawarah Guru Mata Pelajaran) Kimia Kabupaten Bintan, diketahui bahwa minat menulis para guru Kimia di Kabupaten Bintan memang masih rendah. Hal tersebut disebabkan oleh kurangnya motivasi dan pemahaman guru terhadap manfaat yang terkandung dalam hasil tulisan yang dibuat. Di samping itu, guru juga merasa kesulitan dalam mencari sumber referensi yang relevan dan cara-cara mengolah kalimat agar tidak terdeteksi sebagai kegiatan plagiasi. Semua alasan tersebut karena keterbatasan pengetahuan mereka dalam TIK, sehingga karya-karya tulis yang mereka hasilkan dapat dikatakan belum sepenuhnya bebas plagiasi. Pahmi, dkk (2018) masih banyak guru yang belum benar-benar memahami cara penulisan karya ilmiah yang baik termasuk bagaimana cara membuat kutipan daftar pustaka/referensi dengan menggunakan sistem aplikasi komputer, selama ini masih menggunakan sistem manual.

Menyikapi hal yang diakui oleh para guru mengenai keterbatasan-keterbatasan yang mereka miliki, maka tim pengabdian masyarakat memiliki ide untuk memperkenalkan manajemen referensi Mendeley kepada kalangan guru Kimia di Kabupaten Bintan demi meningkatkan hasil karya tulis ilmiah. Tujuan kegiatan ini agar para guru SMA/sederajat di Kabupaten Bintan dapat membuat karya tulis ilmiah yang sesuai kaedah penulisan yang baik dan bebas plagiasi dengan bantuan manajemen referensi Mendeley. 


\section{METODE PELAKSANAAN}

Mitra dalam kegitaan ini adalah guru-guru kimia di kabupaten Bintang. Tempat pelaksanaan kegiatan adalah di Ruang Belajar SMA Negeri 1 Bintan Timur, Kabupaten Bintan, Provinsi Kepulauan Riau. Kegiatan dilaksanakan dalam bentuk pelatihan/workshop yang terbagi ke dalam dua sesi, sesi pertama sebanyak dua kali tatap muka diiringi dengan metode ceramah, diskusi, dan tanya jawab dan sesi kedua dengan metode projek berupa implementasi penggunaan manajemen referensi Mendeley oleh peserta yang diberikan waktu selama dua hari.

Sesi pertama yang dilakukan selama dua kali tatap muka(5-6 September 2018) merupakan bentuk pelatihanyang disampaikan oleh tiga orang narasumber. Secara garis besar, materi pelatihan meliputi (1) urgensi menulis bagi civitas akademik, (2) tata cara penulisan ilmiah, dan (3) implementasi penggunaan manajemen referensi Mendeley. Sesi kedua, berupa pengimplementasian penulisan karya tulis ilmiah berbantukan manajemen referensi Mendeley, dimana peserta diberikan waktu selama dua hari (7-8 September 2018) untuk menyelesaikan draft artikel yang telah dimilikinya dengan mengintegrasikan Mendeley di dalamnya.

Tabel 1. Jadwal Kegiatan

\begin{tabular}{llc}
\hline No. & \multicolumn{1}{c}{ Judul Kegiatan } & $\begin{array}{c}\text { Alokasi Waktu } \\
\text { (JP) }\end{array}$ \\
\hline 1. & Urgensi menulis bagi civitas akademik & 1 \\
2. & Tata cara menulis artikel ilmiah & 2 \\
3. & Tata cara publikasi ilmiah ke dalam Jurnal ber-OJS & 1 \\
4. & $\begin{array}{l}\text { Pembuatan akun Mendeley dan instalasi Mendeley Desktop } \\
\text { 5. }\end{array}$ & 2 \\
& $\begin{array}{l}\text { Tata cara mencari referensi dan penelusuran referensi di } \\
\text { basis data Mendeley }\end{array}$ & 2 \\
6. $\quad \begin{array}{l}\text { Tata cara membubuhkan anotasi dan highlight di dokumen } \\
\text { menggunakan Mendeley }\end{array}$ & 2 \\
7. $\quad \begin{array}{l}\text { Tata cara membuat kutipan dan daftar pustaka secara } \\
\text { otomatis menggunakan Mendeley }\end{array}$ & 2 \\
8. $\quad \begin{array}{l}\text { Tata cara mengatur gaya dan bahasa sitasi menggunakan } \\
\text { 9. } \quad \begin{array}{l}\text { Mendeley } \\
\text { mengukur tingkat plagiasi pada artikel ilmiah yang telah }\end{array}\end{array}$ \\
10. $\quad \begin{array}{l}\text { Implementasi penggunaan manajemen referensi Mendeley } \\
\text { ke dalam karya tulis ilmiah }\end{array}$ \\
\hline Total
\end{tabular}

Total

Instrumen yang diperlukan selama proses pelatihan berlangsung berupa aplikasi Mendeley, lembar kuisioner evaluasi, dan bukti dokumentasi.

\section{HASIL DAN PEMBAHASAN}

Pelaksanaan pengabdian pada masyarakat tentang pelatihan penggunaan menejemen refrensi mendeley terlaksana sesui dengan rencana program yang telah didesai sebelum kegiatan. Kegiatan ini melibatkan guru-guru kimia tingkat SMA Sederajat di Kabupaten Bintan. Adapun hasil dari kegiatan antara lain

1. Kehadiran peserta mencapai $80 \%$ dari total undangan, yaitu sebanyak 25 peserta yang hadir dari 30 peserta undangan. 


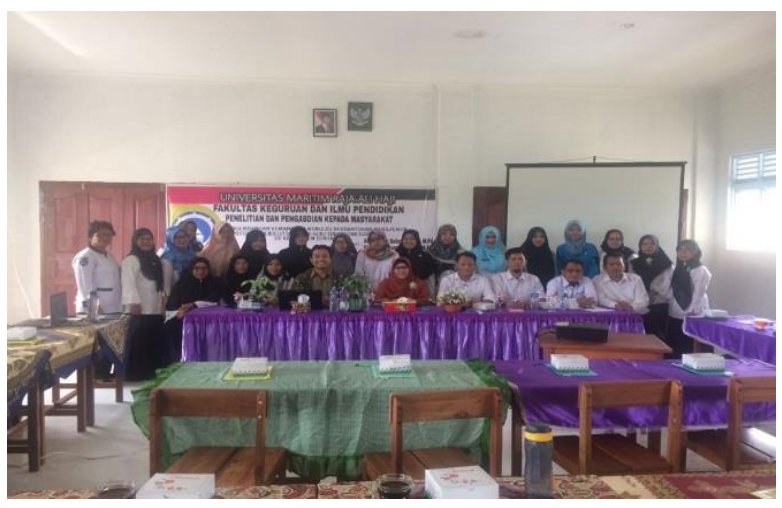

Gambar 1. Poto Bersama Peserta pelatihan

Banyaknya jumlah peserta yan hadir menunjukkan bahwa mereka memiliki minat dan keinginan yang tinggi untuk menggali informasi dan pemahaman tentang penggunaan aplikasi mendeley sebagai bagian penting dalam penulisan karya ilmiah.

2. Berdasarkan observasi yang dilakukan selama kegiatan berlangsung, terlihat bahwa antusias dan minat peserta cukup tinggi yang ditunjukkan dengan keaktifan bertanya peserta dan usahanya untuk memahami materi workshop.

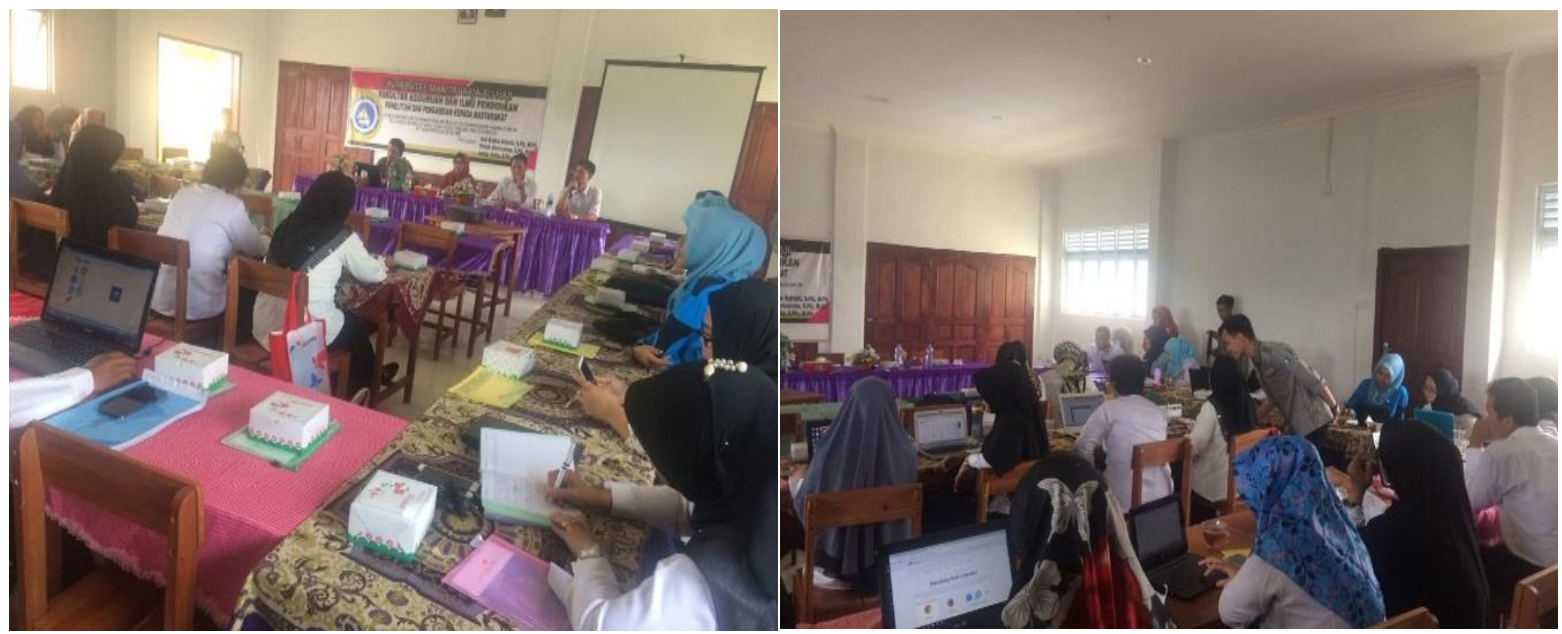

Gambar 2. Aktivitas peserta dalam kegiatan pelatihan

3. Berdasarkan hasil evaluasi setelah pelaksanaan kegiatan selesai, didapatkan bahwa peserta merasakan manfaat yang besar terhadap penggunaan manajemen referensi Mendeley sehingga kegiatan yang dilakukan dapat menambah wawasan peserta (85\%).

Evaluasi yang dilakukan terhadap pelaksanaan kegiatan pelatihan manajemen referensi Mendeley menitikbertakan pada wawasan awal dan wawasan akhir para peserta setelah dilaksanakannya kegiatan tersebut. Di pengetahuan awal peserta, sebanyak $82 \%$ peserta belum pernah mendengar istilah manajemen referensi Mendeley sehingga mereka memang belum menggunakan Mendeley untuk membantu proses penulisan karya ilmiah yang mereka buat.

Setelah kegiatan pelatihan dilakukan, terdapat $87 \%$ peserta yang merasakan bahwa manajemen referensi ini sangat mereka butuhkan dalam proses menulis dan sebanyak $84 \%$ peserta ingin selalu menggunakannya dalam penulisan. Hal tersebut dikarenakan menurut 89\% peserta, manajemen referensi Mendeley memberi kemudahan dalam mebuat sitasi sehingga mampu meminimalisisr tindakan plagiasi dalam penulisan dan juga Mendeley ini mudah diaplikasikan di laptop atau komputer para peserta (83\%). Hasil evaluasi pelaksanaan pengabdian kepada masyarakat ini dapat dilihat pada Tabel 1 sebagai berikut. 
Tabel 2. Hasil Evaluasi Pelaksanaan

\begin{tabular}{clcc}
\hline No. & \multicolumn{1}{c}{ Indikator } & Skor & $\%$ \\
\hline 1 & $\begin{array}{l}\text { Saya belum pernah mengenal istilah "Manajemen Referensi } \\
\text { Mendeley" ini sebelumnya }\end{array}$ & 3,28 & 82 \\
2 & $\begin{array}{l}\text { Setelah mengikuti pelatihan ini, saya menjadi mengenal Manajemen } \\
\text { Referensi Mendeley dengan baik }\end{array}$ & 3,28 & 82 \\
3 & $\begin{array}{l}\text { Setelah mengikuti pelatihan ini, saya merasa Manajemen Referensi } \\
\text { Mendeley sangat dibutuhkan dalam proses menulis }\end{array}$ & 3,48 & 87 \\
4 & $\begin{array}{l}\text { Setelah mengikuti pelatihan ini, saya ingin selalu menggunakan } \\
\text { Manajemen Referensi Mendeley dalam menulis }\end{array}$ & 3,36 & 84 \\
6 & $\begin{array}{l}\text { Manajemen Referensi Mendeley ini memudahkan saya dalam } \\
\text { membuat sitasi dan daftar pustaka }\end{array}$ & 3,56 & 89 \\
7 & $\begin{array}{l}\text { Manajemen Referensi Mendeley ini mampu mengurangi tindakan } \\
\text { plagiasi dalam penulisan }\end{array}$ & $\begin{array}{l}\text { Setelah mengikuti pelatihan Manajemen Referensi Mendeley ini } \\
\text { pengetahuan saya mengenai sitasi semakin bertambah }\end{array}$ & 88 \\
8 & $\begin{array}{l}\text { Manajemen Referensi Mendeley mudah diaplikasikan di laptop atau } \\
\text { komputer }\end{array}$ & 3,32 & 85 \\
\hline
\end{tabular}

Pelaksanaan kegiatan dapat berjalan sesuai harapan tentunya tidak terlepas dari dukungan beberapa pihak, di antaranya dukungan dari pihak LP3M UMRAH, Kepala SMAN1 Bintan Timur yang bersedia menjadi tuan rumah, dan antusiasme para peserta pelatihan yang terdiri dari guru-guru yang tergabung dalam MGMP Kimia SMA Kabupaten Bintan serta guru-guru dari MGMP lainnya di Kabupaten Bintan.

Terselenggaranya kegiatan dengan baik dan lancar, tentunya tidak terlepas dari beberapa faktor penghambat meskipun tidak mengganggu kegiatan secara keseluruhan. Diantaranya, jarak antar sekolah peserta dengan tempat pelaksanaan yang cukup bervariasi jauhnya sehingga memerlukan waktu ekstra untuk menghadirkan peserta dan kondisi wifi yang kurang stabil mengakibatkan beberapa peserta mengalami sedikit keterlambatan dalam mengikuti materi workshop karena tertinggal membuka link internet yang diarahkan, namun dapat diatasi dengan penggunaan hotspot wifi dari tim pelaksana.

\section{KESIMPULAN}

Kegiatan pengabdian kepada masyarakat ini dianggap berhasil dilakukan karena mencapai $80 \%$ kehadiran dan $85 \%$ peserta merasakan manfaat manajemen referensi Mendeley ini dalam membantu meminimalisir kegiatan plagiasi dan mempermudah proses mensitasi dalam penulisan karya tulis ilmiah

\section{REKOMENDASI}

Adapun saran-saran bagi berlangsungnya kegiatan serupa untuk meningkatkan profesionalisme guru yaitu (1) Bagi guru-guru SMA/sederajat di Kabupaten Bintan yang telah mengikuti pelatihan diharapkan dapat menyebarluaskan pengetahuan dan keterampilan yang telah dimiliki kepada guru-guru lain di sekitar tempat tugasnya dan (2) kegiatan pengabdian kepada masyarakat berikutnya dapat diperluas cakupan materinya berupa penggunaan media pembelajaran kreatif dan studi kasus terhadap permasalahan di dunia pendidikan, khususnya pada bidang studi IPA.

\section{UCAPAN TERIMAKASIH}

Ucapan terima kasih disampaikan kepada Universitas Maritim Raja Ali Haji (UMRAH) yang telah memberikan dukungan finansial terhadap program kegiatan pengabdian kepada masyarakat ini.

\section{DAFTAR PUSTAKA}

Agustiana T.A.G.I., Tika N.Y., \& Wibawa C.M.I (2018) Pelatihan Membuat Daftar Isi Dan Daftar Pustaka Dengan Sekali Klik Berbantuan Mendeley Bagi Para Dosen Pts Dalam Menyusun Artikel Dan Laporan Penelitian Se-Kabupaten Buleleng. International 
Journal of Community Service Learning. Volume 2, Number 2, Tahun 2018, pp. 116123

Aji. (2016). Mendeley, Aplikasi Wajib Bagi Kamu Para Mahasiswa. 08/05/2016. https://macpoin.com/13873/mendeley-aplikasi-wajib-bagi-kamu-para-mahasiswa

Cresswell, J. W. (2012), Educational Research: Planning, Conducting, and Evaluating Quantitative and Qualitatitve Research, 4 ed, Boston: Pearson. https://kepri.bps.go.id/. Diakses pada 25 Maret 2018.

Mulyatiningsih, E. 2014. Metode Penelitian Terapan Bidang Pendidikan. Alfabeta:Bandung.

Suryadi, D. 2007. IImu dan Aplikasi Pendidikan Bagian 3 Pendidikan Disiplin IImu Tim Pengembang IImu Pendidikan FIP-UPI. Bandung. PT IMTIMA.

Sugiyono. 2015. Metode Penelitian Pendidikan. Alfabeta: Bandung.

Sukardi. 2007. Metodologi Penelitian Pendidikan. Bumi Aksara: Jakarta

Undang-Undang Republik Indonesia Nomor 14 Tahun 2005 Tentang Guru dan Dosen

Windarto, A. P., Hartama, D., Wanto, A., \& Parlina, I. (2018). Pelatihan Pemanfaatan Mendeley Desktop Sebagai Program Istimewa Untuk Akademisi Dalam Membuat Citasi Karya Ilmiah. AKSIOLOGIYA: Jurnal Pengabdian Kepada Masyarakat, 2(2), 145. https://doi.org/10.30651/aks.v2i2.1319

Pahmi, Ardiyah, Syahfutra W., Wibowo P.A., Niah S., \& Febtiningsih P (2018) Pelatihan Penggunaan Mendeley Untuk Referensi Dalam Menulis Karya IImiah Bagi Guru Sma Handayani Pekanbaru. Jurnal Pengabdian untuk Mu NegeRI. 2(2) 35-39. 